\title{
The Application of Computer Post-Processing Technique in the Abstract Photography Art Expression
}

\author{
Xia SONG ${ }^{1, a}$ \\ ${ }^{1}$ College of art and design, Nanyang institute of technology, Nanyang 473000,China \\ asongxia@126.com
}

\begin{abstract}
Keywords: Network Resources Computer Post-Processing Technique; Abstract Photography; Art Expressive
\end{abstract}

\begin{abstract}
. photography comes into being with the birth of photography, photography in the world history development, occupies important position in the star-studded sky photography art, striking abstract photography master not rare, contend in fragrance and fascination of abstract photography also palpable. Unlike the photography of abstract theoretical research is relatively less abstract theory in the study, analysis from the Angle of the understanding and appreciation to the more abstract photography, to abstract photography creation activities do very enough. If you can from the aspects of creation concept methods or techniques, answer abstract photography are faced with the problem, to promote the healthy development of the emerging art photography, is very necessary. In this paper, the computer post-processing technique in the application of the abstract photography art expressive was studied, as abstract photography art performance and innovation provides a new perspective.
\end{abstract}

\section{Background}

At the dawn of photography, can shoot some pictures of black and white, in the form of a film to photograph, because of the modern electronic computer has not been formed, there would be no any post-processing work, can only be present when shooting pictures, with the progress of photographic equipment, there are more and more advanced equipment, can not only to the static image, and to capture the dynamic image and sound, but compared with the people to see the actual picture, still exist some gaps in the quality. In this context, the study of how to close the gap, and found that through a lot of practice to improve the quality of the display screen and filming equipment performance, to a certain extent, improve the quality of the picture, if you use some computer software, to deal with captured images, etc., also can achieve this goal, this is the original concept of photography post-processing, after years of development, filming equipment performance has been greatly improved, captured images have been able to meet the needs of the people. Therefore post-processing work idea and corresponding changes have taken place, and now the post-processing, the main use of high-tech means, to add some special effect, or by simulation technology etc., some can't captured images, especially in film production, the scenarios involved, and some science fiction movies, apparently unable to field, can decorate some temporary scenario, need high cost, if the computer carries on the post-processing technology, can largely reduce the cost of this part.

\section{The concept and characteristics of abstract photography}

In our line of sight in the world though is representational, but all constitute a representational local or detail is abstract. But we normally do not pay attention to find abstract in the real world. Abstract factors are everywhere, water lines, shaking reflection, variation of the projection, light and shade, mottled old wall, rain drip marks, reinforced the line of confusion, building structure, etc., all will object to the original appearance of local and details, can make the abstract pattern, when photography to find and select grab image, by the light and shade, bright and dark, point and line, surface and composition, color and texture of images, is an abstract photography. Abstract photography has a broad prospect in China. 
Abstract photography is abstract art. Irrational characteristics of abstract art makes aesthetics in artistic appreciation is to think without thinking, thinking though very tired, but is also the most simple to think, because thinking is the answer, the answer is simple. And direct aesthetic, touch screen, directly with visual communication and work directly with the discrimination ability of the instinct, although at this time there is no language can express, but "silent sound" at this time, wordless communication can speak understand language communication more room for imagination and extension of space. Abstract art is in this sense was established.

Abstract art is the art of the original, can be arbitrary arrangement with color, line, composition, details of art space, can be found in the optional daub inspiration and select the essence. Abstract photography because of the special equipment of lens are born in the face of reality, appearing in the camera viewfinder can be to live and can't be abstract images, photography how to represent a pure visual form, this is probably confused by a lot of photography enthusiasts.

\section{The characteristics and application of Photoshop for abstract photography}

Developed by a world famous software company, Adobe Photoshop is one of the most prominent, the most famous and most commonly used image processing software, is widely applied. It combines the image change, creative production, input and output, scanning image is equal to one, can be a variety of formats of input and output function, support various color modes at the same time, convenient and quick, choose a variety of functional image and image editing, color adjustment, most graphic designer. Some applications Abstract photography based on PS is shown in figure 1.

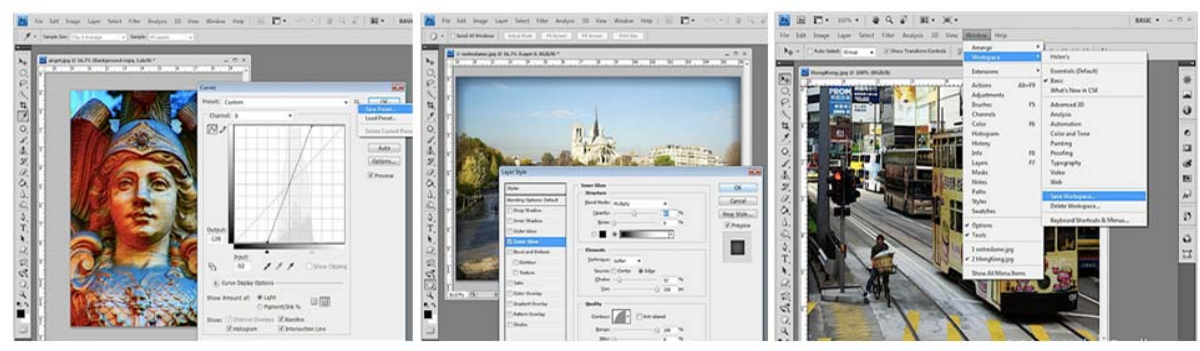

Figure 1. The applications of Photoshop

Photoshop is one of the most typical and most authoritative tone effect, it can be fast and easy to adjust and modify the image brightness of color, deviation adjusting color, can also meet the different color image in all aspects of your application. Each picture or image, image synthesis is through the layer of operation, select the application, finally combined into a new image [2]. And the Photoshop will be a very good drawing tools can be their own ideas and select external image fusion, combined with the designers need to image. Special effects production mainly depends on the channel, the tools in Photoshop, masks, filters and other comprehensive tools to complete. For example, the special word to create special effects to create the image, photosynthetic efficiency, design and production of gypsum social life paintings, reliefs, wood often use Photoshop completed effects.

\section{The characteristics and application of Lightroom for abstract photography}

Lightroom is Adobe launched a graphical tools, focusing on the post-production Adobe's goal is to make the future standard on the digital image processing, Lightroom interface and function with apple echoed Aperture launched in October 2005, primarily to digital photography, graphic design and other professional and high-end users, support a variety of RAW images, mainly used for browsing, editing, digital photo finishing, printing, etc. Some application for abstract photography -based on Lightroom are to in figure2. 


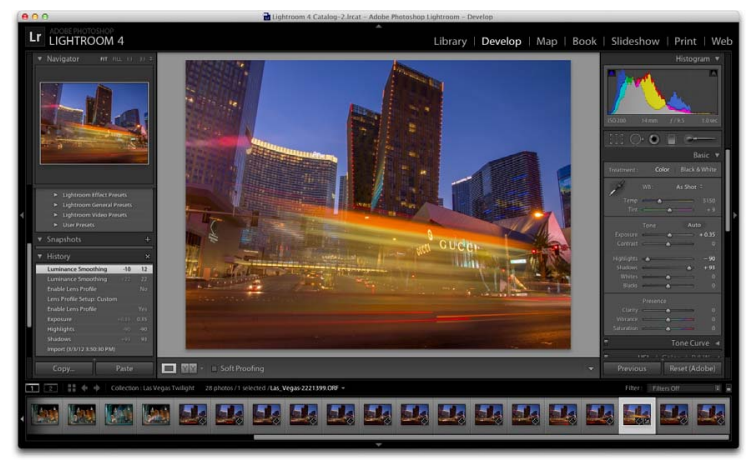

Figure 2. The applications of Lightroom

Lightroom has many similarities with Photoshop, but different positioning, won't be replaced, and Photoshop on many functions, such as the selection tool, photographs, defect correction, multiple file synthesis tools, the text tool and filter Lightroom does not provide. At the same time, the Windows version of the Lightroom has lost its Mac OS X version of some functions, such as slide background music, camera and memory card monitoring function, HTML slide creation tools, etc. Adobe, after acquisition of digital photo software company Pigmented Denmark ApS received the latter RawShooter software for digital camera, the workflow management, processing technology and so on have been integrated into the Windows version of Lightroom. Adobe officially released the Photoshop Lightroom 4 software, Lightroom 4 on the basis of the previous generation joined the books and maps module, provides the albums production and marking location, and other functions, and increase the support for video files [2]. Lightroom camera support, according to the different versions, and supported by the camera is different; Lightroom will be updated according to the camera, and constantly update their products software upgrades. Adobe Photoshop Lightroom can quickly import and processing management photos by the photographer in love, she is able to greatly improve the work efficiency of the photographer.

\section{Abstract photography late computer technology application in post processing}

The use of advanced processing software. To the maximum extent, improve the effect of post processing of photography, must use the latest computer processing software, due to the use of computer technology, mainly in the form of software, and between different software, there is a big difference, through the actual investigation found that at present, there are a lot of post-processing software on the market, companies according to different needs, targeted processing software developed based on their own understanding, each software has distinctive features, so in the actual choice, should according to the effect of the need to deal with. Should be paid attention to in choosing a good processing software, software updates, because the software in writing is finished, there are a lot of problems, so every once in a while, the software company will launch a new version, at the same time, to repair the problem such as bugs will also add some new functions, for the post-processing of photography, is a timely work, in a certain period, a kind of special treatment effect, will be very popular with people, if you can timely update software, you can catch the chance. Now photography in the post-processing, the use of computer software is very common, and even a lot of individual users, after in the image, also can choose to use some software carries on the post-processing, compared with television, film production, the processing is simpler, are some of the basic processing, can't add complex scenarios effects, the key causes of such differences, is the use of different processing software, thus it can be seen that the importance of computer software for post-processing of photography..

Using advanced computer hardware equipment. Computer technology can be divided into two parts of hardware and software, and the post-processing of photography, in order to achieve better treatment effect, in addition to the necessary computer software, also need to pay attention to the hardware, the hardware as the foundation of the software, is an important guarantee of software running efficiency, especially in today's software is more and more complex, photography post 
processing, usually need to add a lot of scenes, computer larger workload, if the hardware performance is not guaranteed, so the software execution efficiency will decrease. In the actual photography post-processing, also can use some special equipment, in a sense, the equipment belongs to the category of computer technology, the equipment can only carry on the type of effect processing, have very strong pertinence, but compared with the traditional computer software, the treatment effect is much better, so in the film and television production, application scope is very broad, in this context, in order to guarantee the effect of post processing of photography, must use the advanced equipment for processing.

\section{Conclusion}

It is in the form of abstract photography, keen to in limited forms of pursuing and mining is containing the infinite spirit connotation of its composing style is completely different from other types of photography. It has no obvious theme. Also is to identify the plot. Even without a clear and specific. Only some simple form or be a separate feature of the object image emphasized. Watch cannot according to worldly ways to read to understand. It's just something from under the specific circumstances of the instant ignored, brain wave, experience and inner feeling, so when the appreciation and evaluation of various abstract photography. Abstract photography is photography creation of a class of the most simple and most complex.

\section{References}

[1] K. Tallon : Digital fashion illustration with Photoshop and Illustrator (Anova Books, 2010).

[2] Z.Y. Mei, and C.J. Jie: Advanced Computer Theory and Engineering (Chengdu, China, August 20-22, 2010), Vol.3, p.75

[3] M.B. Codur: Procedia-Social and Behavioral Sciences, Vol. 8 (2011) No.1, p. 2879

[4] Z. FU, X. GONG, and X. CHEN: Journal of Hubei Normal University (Natural Science), Vol.4 (20058), p.17.

[5] H. Fang, and J. Liu: Computer-Aided Industrial Design \& Conceptual Design (Yiwu, China November 17-19, 2012), Vol.1, p.733 